\title{
Protective Effect of Melatonin on Cisplatin-induced Ototoxicity in Rats
}

\author{
JULIANA GUSMÃO DE ARAUJO ${ }^{1 \#}$, LUCIENY SILVA MARTINS SERRA ${ }^{1 \#}$, LUCAS LAUAND ${ }^{2 \#, ~}$ \\ SELMA APARECIDA SOUZA KÜCKELHAUS ${ }^{2 \#}$ and ANDRÉ LUIZ LOPES SAMPAIO ${ }^{1 \#}$ \\ ${ }^{1}$ Laboratory of Otorhinolaringology, Faculty of Medicine, University of Brasilia, Brasilia, Brazil; \\ ${ }^{2}$ Area of Morphology, Faculty of Medicine, University of Brasilia, Brasilia, Brazil
}

\begin{abstract}
Background/Aim: Cisplatin is a highly effective chemotherapeutic agent that is used to treat solid tumors; however, its severe side effects remain a limitation. In particular, the high incidence of cisplatin-induced ototoxicity has attracted interest. Melatonin has been shown to decrease the toxic effects of cisplatin due to its antioxidant activity, and could increase the efficacy of cancer chemotherapy. The aim of this study was to determine the effect of melatonin against ototoxicity in rats treated with cisplatin. Materials and Methods: Rats were randomly divided into four groups (saline, melatonin, cisplatin+saline, and melatonin+cisplatin). Distortion-product otoacoustic emission (DPOAE) measurements were carried out on days 1 and 8. Results: There was a decrease in DPOAE amplitudes in the animals that received cisplatin $(10 \mathrm{mg} / \mathrm{kg})$; however, the group treated with cisplatin+melatonin presented DPOAE amplitudes comparable to those of the control groups. Conclusion: Melatonin can be used as an adjuvant tumor treatment due to its ability to decrease cisplatin-induced ototoxicity.
\end{abstract}

Cancer is currently a leading cause of death in both economically developed and less developed countries (1). Moreover, the global trend toward a shift in lifestyle habits that are known to increase the risk of cancer in less economically developed countries, comprising $82 \%$ of the world's population, is expected to lead to an increase in the number of new cancer cases in the next few years along with population growth and aging (1).

\#Current address: Campus Universitário Darcy Ribeiro, Brasilia, Brazil.

Correspondence to: André Luiz Lopes Sampaio, Campus Universitário Darcy Ribeiro, Faculdade de Medicina, Distrito Federal, 70910-900 Brasília, Brazil. Tel: +55 6120285580, e-mail: andremarjy@uol.com.br Orcid: https://orcid.org/0000-0001-7611-1303

Key Words: Ototoxicity, cisplatin, melatonin, otoacoustic emissions.
Cancer chemotherapy was introduced in the 1940s when nitrogen mustard was first used in clinical practice. In 1969, Rosenberg et al. (2) first demonstrated the cytotoxic effect of cisplatin, and a new class of antitumor agents emerged (2). Although additional platinum analogues are clinically applied, cisplatin is still considered the most useful of these agents based on its versatility, long research history, and supportive literature (3). Indeed, cisplatin remains a highly effective chemotherapeutic agent that is widely used to treat solid tumors, including tumors of the ovary, testis, bladder, lung, and head and neck (4-6). In particular, cisplatin is one of the most effective chemotherapeutic agents for pediatric cancer patients, with an average cure rate of $85 \%(7,8)$.

The mechanism of cisplatin's antitumor activity essentially involves the binding of the drug to DNA and non-DNA targets. The damage induced by the binding of cisplatin to DNA inhibits DNA replication mechanisms, leading to cell death through apoptosis and necrosis of tumor cells (9).

In clinical practice, the dose of cisplatin may be limited owing to its toxic side-effects such as nephrotoxicity, genotoxicity, neurotoxicity, and ototoxicity, often leading to a worse prognosis. Moreover, cancer patients, especially children, have a higher incidence of development of secondary tumors after cisplatin-based treatments, particularly in the proliferative organs. This is due to the genotoxic effects of the drug, which can affect all types of cells in the body and enhance cancer occurrence, particularly leukemia (10).

Ototoxicity has attracted substantial interest due to its higher incidence compared to the other side-effects, being considered the most common dose-limiting side-effect of cisplatin treatment $(4,6,7,11)$. There is still no proven effective treatment to prevent, or at least reduce cisplatininduced ototoxicity. Although increasing saline hydration and mannitol diuresis can ameliorate cisplatin nephrotoxicity, these measures do not have the same effects on ototoxicity (12).

Audiometric studies have indicated an elevation of the hearing threshold in $75-100 \%$ of patients treated with cisplatin (8). This cisplatin-induced ototoxicity risk can be increased by certain factors such as younger age in children, larger 
cumulative doses, renal disease, previous hearing loss, and irradiation of the skull base $(13,14)$. Although the ototoxicity usually occurs within hours to days after drug administration, delayed ototoxicity from cisplatin has also been reported in children (4). The severity of the ototoxic effect is also positively correlated to the cumulative dose of cisplatin $(15,16)$.

Cisplatin-induced ototoxicity begins with damage to the outer hair cells at the base of the cochlea, resulting in a predominantly high-frequency hearing loss even at low doses. As the treatment continues or the dose increases, the cochlear lesion spreads apically, resulting in additional hearing loss in the mid-to-high-frequencies (17). In addition, cisplatin may affect other regions of the cochlea such as the stria vascularis, spiral ligament, and spiral ganglion $(18,19)$.

Cochlear tissues from animals receiving ototoxic doses of cisplatin are depleted of glutathione and antioxidant enzymes (superoxide dismutase, catalase, glutathione peroxidase, and glutathione reductase). Malondialdehyde levels increase, which is an indicator of lipid peroxidation $(13,20)$. In 2007, Rybak et al. (21) reviewed research findings that provide insights into the mechanism underlying cisplatin ototoxicity. In particular, they described that the depletion of cochlear antioxidant enzyme activities may be a result of the direct binding of cisplatin to essential sulfhydryl groups within the enzymes (21).

Some drugs have been reported to show potential protective effects against cisplatin ototoxicity. However, some of these failed in safety assessments and could eventually reduce the anti-neoplastic activity of cisplatin, which would lead to disastrous effects for the patient's prognosis. Thus, there is an urgent need to identify substances capable of protecting against the ototoxicity of cisplatin, since this side effect causes significant morbidity to patients.

Melatonin is widely distributed in animals and has an uncommonly wide range of functions (22). The production of melatonin increases during the absence of light and is maintained at minimal levels in the presence of light, giving rise to a circadian rhythm imposed by the light/dark cycle (23). Accordingly, melatonin is also a sleep promoter and regulator of photoperiod-dependent seasonal reproduction in some vertebrates (24). In addition, melatonin has direct free radical-scavenging activity and also regulates gene transcription of antioxidative enzymes (25). Melatonin also seems to decrease the toxicity and increase the efficacy of cancer chemotherapy (26-28).

Although melatonin has already been shown to be effective against cisplatin-induced nephrotoxicity, testicular toxicity, oxidative stress, and genotoxicity (29-32), its protective effect against ototoxicity remains unclear. Considering the antioxidant effect of melatonin, in this study, we examined its ability to protect against the ototoxicity in rats treated with a single dose of cisplatin. To our knowledge, this is the first assessment of the protective effect of melatonin alone, by systemic administration, against cisplatin-induced ototoxicity.

\section{Materials and Methods}

Animals and study groups. Female Wistar rats (3 months old) obtained from the University of Goiás were used in this study. The rats were maintained in the biotery, during the experimental phase under a controlled room temperature of $25 \pm 3^{\circ} \mathrm{C}$ with a $12-\mathrm{h}$ light/dark cycle, were fed a balanced diet and provided water $\mathrm{ad}$ libitum. All experiments were performed according to the protocol approved by the Ethics Committee on Animal Use on 02/24/2015 (UnBDOc no. 7117/2015).

Before collecting the data, all the animals underwent otoscopy to verify the presence of external and middle ear disorders. Only animals confirmed to have no alterations in the exam were included in the study. These rats were then randomly divided into four groups: control saline $(n=5)$, control melatonin $(n=5)$, cisplatin+ saline $(n=12)$, and cisplatin+melatonin $(n=10)$. The saline and melatonin $(1 \mathrm{mg} / \mathrm{kg})$ solutions were administered daily, whereas the cisplatin solution $(10 \mathrm{mg} / \mathrm{kg})$ was administered only on the fourth day (D4). All solutions were injected intraperitoneally.

Ototoxicity evaluation. Distortion-product otoacoustic emissions (DPOAE) measurements were carried out for each group on day 1 (D1, i.e., the day of administration) and day 8 (D8) of the trial. Prior to the assessment, the rats were anesthetized $(30 \mathrm{mg} / \mathrm{kg}$ of ketamine hydrochloride and $7 \mathrm{mg} / \mathrm{kg}$ of xylazine) and placed in a soundproof box allocated in a silent room.

DPOAEs were assessed with an ILO292 II (Otodynamics Ltd, Hatfield, UK). An infant hearing-screening probe was attached to the external auditory canal. The stimulus consisted of two pure tones (F1 and F2; F1/F2 ratio=1.22) at $70 \mathrm{~dB}$ SPL. In total, a thousand acquisitions were analyzed. The resulting otoacoustic emissions were evaluated at 2.8, 4, 6 and $8 \mathrm{kHz}$. After data collection, all animals were euthanized with $\mathrm{CO}_{2}$ under anesthesia after conclusion of the experiments.

Statistical analysis. The normality of variables was analyzed by the Kolmogorov-Smirnov test, and the variance homogeneity was analyzed by the Bartlet test. Kruskal-Wallis followed by Dunn's post-hoc test was used to compare non-parametric samples of each group on D1 and D8. The Wilcoxon test was used to compare two dependent non-normal samples to pinpoint the significant differences between D1 and D8. The paired $t$-test (two-tailed) was used to compare two dependent normal samples to pinpoint the significant differences between D1 and D8. The Prism ${ }^{\circledR}$ Software Package program (GraphPad, USA, 2005) was used for statistical analyses and for graphical representations; values of $p<0.05$ were considered statistically significant.

\section{Results}

There were no differences in DPOAE amplitudes evaluated on day 1 among the four groups, for all frequencies (Kruskal-Wallis/Dunn method; $2.8 \mathrm{kHz}, p=0.194 ; 4.0 \mathrm{kHz}$, $p=0.212 ; 6.0 \mathrm{kHz}, p=0.114 ; 8.0 \mathrm{kHz}, p=0.414)$. In addition, at the second evaluation (D8), the DPOAE amplitude values were lower in the cisplatin+saline treatment group compared to that of the saline group at all frequencies (KruskalWallis/Dunn method; $2.8 \mathrm{kHz}, p=0.011 ; 4.0 \mathrm{kHz}, p=0.049$; $6.0 \mathrm{kHz}, p=0.047 ; 8.0 \mathrm{kHz}, p=0.030$ ). However, the DPOAE 
Table I. Distortion-product otoacoustic emissions (DPOAE, dB SPL) evaluated on the first (D1) and eighth (D8) days in all groups studied.

\begin{tabular}{|c|c|c|c|c|c|c|c|c|}
\hline \multirow{2}{*}{$\begin{array}{l}\text { Evoked frequencies }(\rightarrow) \\
\text { Groups }(\downarrow)\end{array}$} & \multicolumn{2}{|c|}{$2.8 \mathrm{kHz}$} & \multicolumn{2}{|c|}{$4.0 \mathrm{kHz}$} & \multicolumn{2}{|c|}{$6.0 \mathrm{kHz}$} & \multicolumn{2}{|c|}{$8.0 \mathrm{kHz}$} \\
\hline & D1 & D8 & D1 & D8 & D1 & D8 & D1 & D8 \\
\hline Saline & 11.9 & 11.7 & 22.8 & 23.7 & 35.5 & 32.8 & 33.1 & 33.2 \\
\hline Melatonin & 11.3 & 11.0 & 20.1 & 19.8 & 31.2 & 32.0 & 30.9 & 32.8 \\
\hline Cisplatin+saline & 11.8 & $8.1 *$ & 22.8 & $16.8^{*}$ & 33.8 & $25.6^{*}$ & 33.1 & $28.6^{*}$ \\
\hline Cisplatin+melatonin & 11.4 & 11.7 & 20.0 & 20.4 & 31.9 & 29.5 & 33.8 & 29.3 \\
\hline
\end{tabular}

Data are expressed as median values. *Values that significantly differ $(p<0.05)$ from those of the saline group.

amplitude values did not differ between the saline and melatonin or cisplatin+melatonin groups (Table I).

In the pairwise analyses, the means \pm SD of DPOAE did not differ between D1 and D8 in either the saline $(2.8 \mathrm{kHz}$ $p=0.600 ; 4.0 \mathrm{kHz} p=0.528 ; 6.0 \mathrm{kHz} p=0.132 ; 8 \mathrm{kHz}$ $p=0.688)$ or melatonin $(2.8 \mathrm{kHz} p=0.990 ; 4.0 \mathrm{kHz} p=0.825$; $6.0 \mathrm{kHz} p=0.260 ; 8 \mathrm{kHz} p=0.240$ ) groups in all frequencies tested (Figure 1).

Moreover, there were no differences in DPOAE amplitudes obtained on D1 and D8 of treatment at 2.8, 4.0,6.0 and 8.0 $\mathrm{kHz}$ in the cisplatin+melatonin group $(2.8 \mathrm{kHz} p=0.495 ; 4.0$ $\mathrm{kHz} p=0.292 ; 6.0 \mathrm{kHz} p=0.223 ; 8 \mathrm{kHz} p=0.087$ ) (Figure 1).

However, in the cisplatin+saline group, the DPOAE amplitudes were significantly higher on day 1 than on day 8 , for all frequencies $(2.8 \mathrm{kHz} p=0.009 ; 4.0 \mathrm{kHz} p=0.006 ; 6.0$ $\mathrm{kHz} p=0.003 ; 8 \mathrm{kHz} p=0.010$ ) (Figure 1).

\section{Discussion}

The prevention of cisplatin side-effects remains a major clinical problem to improve, affection the therapeutic efficacy and quality of life of cancer patients under treatment. In particular, cisplatin-induced ototoxicity is the key side-effect contributing to chemotherapy dose reduction that can compromise the effectiveness of the treatment.

Herein, we confirmed that a single dose of cisplatin $(10 \mathrm{mg} / \mathrm{kg})$ to rats decreased the DPOAE amplitudes; however, early and concomitant treatment with melatonin resulted in comparable DPOAE amplitudes to those of the control groups (saline and melatonin alone) at all frequencies, demonstrating its ability to protect against cisplatin-induced ototoxicity.

Other antioxidant agents administered in combination with cisplatin have been also suggested; however, none of these agents has become part of routine clinical use owing to the time required to carry out careful safety evaluations of any drug that is deemed to be potentially useful in reducing chemotherapy-related side-effects. First, it is essential to assess the candidate drug's toxicity and analyze its effects on cancer treatment. Second, the effects of the drug on tumor remission and patient survival must be carefully tested.
Melatonin has already been widely tested in different animal species over a wide range of doses from physiological to high pharmacologic concentrations to determine its potential toxicity, and no major unfavorable effects have been reported, even at high doses. In general, the doses of melatonin administered in vivo reach up to 100 $\mathrm{mg} / \mathrm{kg}$ body weight in rats (33) and $250 \mathrm{mg} / \mathrm{kg}$ body weight in mice (34). Even when administered at massive doses (up to $200 \mathrm{mg} / \mathrm{kg}$ body weight) during pregnancy, melatonin did not induce significant embryo/fetal toxicity (35). Consistently, we did not observe any side effects of the use of melatonin at the proposed dose in the present study.

In a study of advance non-small cell lung cancer, patients treated with melatonin had better health-related quality of life scores. A great amount of DNA damage marker was observed in the placebo-treated group, implying the protective effect of melatonin in healthy cells. However, melatonin in combination with chemotherapy did not affect survival and adverse events, maybe because the study has a limited sample size and a population with potentially poor prognosis (36). Furthermore, melatonin co-treatment may be an effective strategy for patients with drug-resistant colorectal cancer (37).

A meta-analysis published in 2005 demonstrated consistent improvement in the 1-year survival rate with melatonin adjunct therapy in a variety of patients with advanced- stage cancers, with low numbers of serious adverse events and low cost (38). In 2012, Wang et al. (39) published an updated meta-analysis of randomized controlled trials that evaluated the efficacy and safety of melatonin used concurrently with chemotherapy or radiotherapy for solid tumors. In most of the included studies, melatonin therapy led to higher tumor remission; better 1-year survival, and less radiochemotherapy-related side effects such as thrombocytopenia, neurotoxicity, and fatigue.

Our favorable results demonstrating the prevention of cisplatin-induced ototoxicity with melatonin administration, along with its established safety during treatment and beneficial effect on prognosis, collectively suggest that melatonin may be an excellent option for the prevention of ototoxicity under 
A

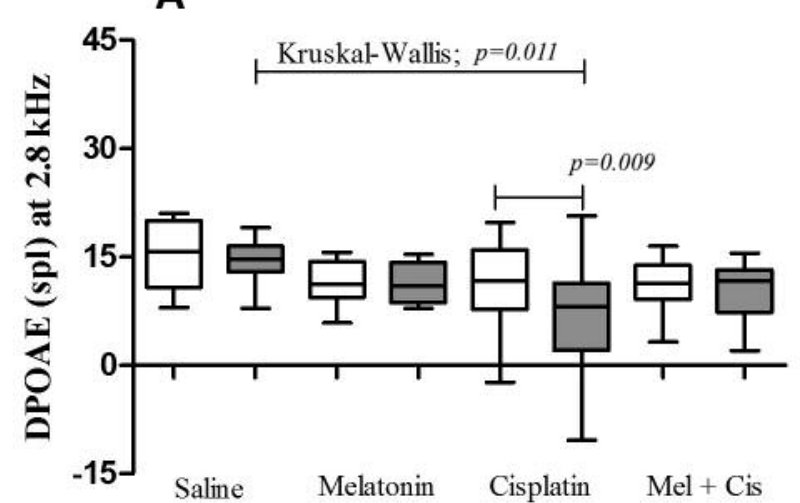

C

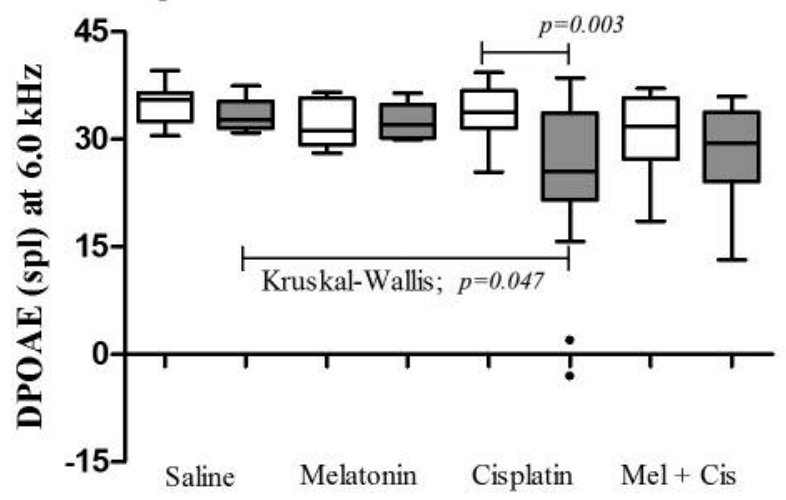

B

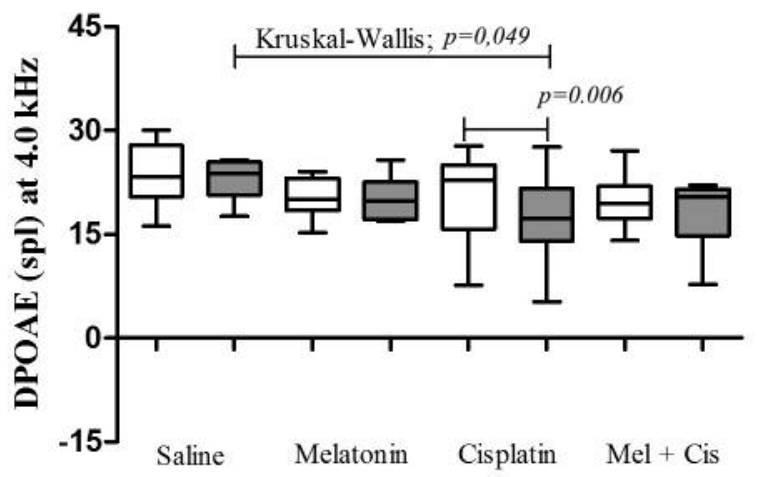

D

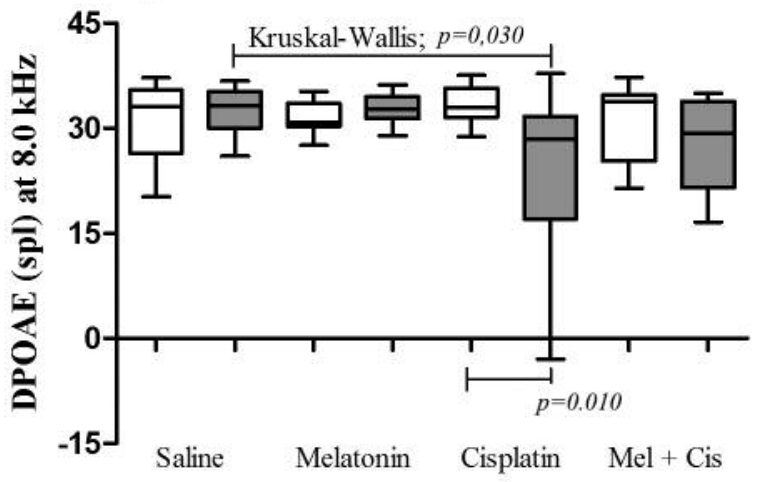

Day $1 \square$ Day 8

Figure 1. Distortion product otoacoustic emissions (DPOAE) amplitudes on day 1 (D1) and day 8 (D8).

cisplatin-based regimes. Although the precise mechanism of these beneficial effects requires further study, it is likely related to the antioxidant activities of melatonin. It is well known that cisplatin imposes severe oxidative stress to the renal tissue, and melatonin has been suggested to protect against this oxidative damage $(40,41)$ potentially via its radical scavenging activity, glutathione peroxidase-activating property, and regulatory activity of renal function $(21,31,42)$. Moreover, Kilic et al. (43) suggested that melatonin attenuates cisplatin-induced nephrotoxicity possibly by modulating Nrf2/HO-1 signaling.

The reproductive system is particularly vulnerable to chemotherapy, as many drugs can cause infertility, changes in organ structure or function, as well as sexual hormones dysfunction (44). Melatonin has cytoprotective effects on the reproductive system (45). In addition to the free radicals scavenging and antioxidant enzymes modulation, melatonin ameliorates reproductive injury through modulating sexual hormones (45). In particular, combined treatment with melatonin has been shown to greatly prevent the marked impairment of testicular function caused by cisplatin in rats (32). In addition, melatonin could significantly improve the decrease in body and testicular weight; epididymal sperm count, motility, and morphology; glutathione peroxidase activity; and glutathione levels in rats under cisplatin treatment (29).

Furthermore, melatonin has been reported to show a protective effect against gentamicin and tobramycin-induced ototoxicity, which did not interfere with the antibiotic capacity of these antibiotics $(46,47)$.

In the present study, $10 \mathrm{mg} / \mathrm{kg}$ cisplatin clearly triggered ototoxicity, as determined by the decrease in DPOAE amplitudes measured at different frequencies, which was prevented by co-administration with melatonin. In addition, administration of melatonin alone did not affect the DPOAE amplitudes measurements of the animals, confirming its safety.

Although the protective effect of melatonin against cisplatin-induced ototoxicity in rats was detected at all frequencies studied, the effect was more evident at the lower frequencies of $2.8,4$, and $6 \mathrm{kHz}$ than that observed at $8 \mathrm{kHz}$, although the effect was still statistically significant. This may be due to the stronger ototoxic effect that is classically described at higher frequencies. Thus, it is possible that 
increasing the melatonin dose could help to maximize its effect, particularly at higher frequencies.

Our results point to the applicability of melatonin as an adjuvant in carcinoma treatment, since it may decrease the ototoxicity caused by cisplatin. In addition, our results should motivate further research to identify the cochlear structural changes caused by cisplatin and its possible reversal with different doses of melatonin. The use of melatonin as an adjuvant in humans to avoid undesirable side-effects of cisplatin is an important goal for the future.

\section{Conflicts of Interest}

There are no conflicts of interest to declare regarding this study.

\section{Authors' Contributions}

Juliana Gusmão de Araujo, Lucieny Silva Martins Serra, Selma Aparecida Souza Kuckelhaus and André Luiz Lopes Sampaio conceived and planned the experiments. Juliana Gusmão de Araujo, Lucieny Silva Martins Serra and Lucas Lauand carried out the experiments for acquisition of data. Juliana Gusmão de Araujo, Lucieny Silva Martins Serra, Selma Aparecida Souza Kuckelhaus, Lucas Laund and André Luiz Lopes Sampaio contributed to sample preparation. Juliana Gusmão de Araujo and Selma Aparecida Souza Kuckelhaus carried out the statistical analysis. Juliana Gusmão de Araujo, Lucieny Silva Martins Serra, Selma Aparecida Souza Kuckelhaus and André Luiz Lopes Sampaio contributed to the interpretation of the results. Juliana Gusmão de Araujo took the lead in writing the manuscript. All Authors provided critical feedback and helped shape the research, analysis and manuscript. All Authors approved the article.

\section{References}

1 Torre LA, Bray F, Siegel RL, Ferlay J, Lortet-tieulent J and Jemal A: Global Cancer Statistics, 2012. CA a Cancer J Clin 65: 87-108, 2015. PMID: 25651787. DOI: 10.3322/caac. 21262

2 Rosenberg B, VanCamp L, Trosko JE and Mansour VH: Platinum compounds: a new class of potent antitumour agents. Nature 222: 385-386, 1969. PMID: 5782119. DOI: 10.1038/ 222385a0

3 Vijayalaxmi, Thomas CR, Reiter RJ and Herman TS: Melatonin: From basic research to cancer treatment clinics. J Clin Oncol 20: 2575-2601, 2002. PMID: 12011138. DOI: 10.1200/JCO. 2002.11 .004

4 Rybak LP, Mukherjea D, Jajoo S and Ramkumar V: Cisplatin ototoxicity and protection: clinical and experimental studies. Tohoku J Exp Med 219: 177-186, 2009. PMID: 19851045. DOI: $0.1620 /$ tjem.219.177

5 Callejo A, Sedó-Cabezón L, Juan I and Llorens J: Cisplatininduced ototoxicity: effects, mechanisms and protection strategies. Toxics 3: 268-293, 2015. PMID: 29051464. DOI: 10.3390/toxics3030268

6 Ekborn A: Cisplatin-induced ototoxicity. Pharmacokinetics, prediction and prevention, Stockholm, Sweden, 2003. Available from: https://openarchive.ki.se/xmlui/bitstream/handle/10616/ 38208/thesis.pdf?sequence $=1$ \&isAllowed $=\mathrm{y}$

7 Mukherjea D and Rybak LP: Pharmacogenomics of cisplatininduced ototoxicity. Pharmacogenomics 12: 1039-1050, 2011.
PMID: 21787192. DOI: $10.2217 /$ pgs. 11.48

8 McKeage MJ: Comparative adverse effect profiles of platinum drugs. Drug Saf 13: 228-244, 1995. PMID: 8573296. DOI: 10.2165/00002018-199513040-00003

9 Cepeda V, Fuertes MA, Castilla J, Alonso C, Quevedo C and Pérez JM: Biochemical mechanisms of cisplatin cytotoxicity. Anticancer Agents Med Chem 7: 3-18, 2007. PMID: 17266502. DOI: $10.2174 / 187152007779314044$

10 Choudhury RC, Jagdale MB and Misra S: Cytogenetic toxicity of cisplatin in bone marrow cells of Swiss mice. J Chemother 12: 173182, 2000. PMID: 10789558. DOI: 10.1179/joc.2000. 12.2.173

11 Rybak LP: Mechanisms of cisplatin ototoxicity and progress in otoprotection. Curr Opin Otolaryngol Head Neck Surg 15: 364369, 2007. PMID: 17823555. DOI: 10.1097/MOO.0b013e3 282eee 452

12 Araujo JG De, Luiz A, Sampaio L, Venosa AR and Oliveira CACP: The potential use of melatonin for preventing cisplatin ototoxicity: an insight for a clinical approach. Adv Otolaryngol 2014: 1-7, 2014. DOI: 10.1155/2014/18561.

13 Tabuchi K, Nishimura B, Nakamagoe M, Hayashi K, Nakayama $\mathrm{M}$ and Hara A: Ototoxicity: Mechanisms of cochlear impairment and its prevention. Curr Med Chem 18: 4866-4871, 2011. PMID: 21919841. DOI: $10.2174 / 092986711797535254$

$14 \mathrm{Li} \mathrm{Y,} \mathrm{Womer} \mathrm{RB} \mathrm{and} \mathrm{Silber} \mathrm{JH:} \mathrm{Predicting} \mathrm{cisplatin} \mathrm{ototoxicity}$ in children: The influence of age and the cumulative dose. Eur J Cancer 40: 2445-2451, 2004. PMID: 15519518. DOI: 10.1016/ j.ejca.2003.08.009

15 Choi SJ, Kim SW, Lee JB, Lim HJ, Kim YJ, Tian C, So HS, Park R and Choung YH: Gingko biloba extracts protect auditory hair cells from cisplatin-induced ototoxicity by inhibiting perturbation of gap junctional intercellular communication. Neuroscience 244: 49-61, 2013. PMID: 23583760. DOI: 10.1016/j.neuroscience.2013.04.001

16 Reddel RR, Kefford RF, Grant JM, Coates AS, Fox RM and Tattersall $\mathrm{MH}$ : Ototoxicity in patients receiving cisplatin: importance of dose and method of drug administration. Cancer Treat Rep 66: 19-23, 1982. PMID: 7198012.

17 Madasu R, Ruckenstein MJ, Leake F, Steere E and Robbins KT: Ototoxic effects of supradose cisplatin with sodium thiosulfate neutralization in patients with head and neck cancer. Arch Otolaryngol Head Neck Surg 123: 978-981, 1997. PMID: 93055250. DOI: 10.1001/archotol.1997.01900090094014

18 Sluyter S, Klis SF, de Groot JC and Smoorenburg GF: Alterations in the stria vascularis in relation to cisplatin ototoxicity and recovery. Hear Res 185: 49-56, 2003. PMID: 14599692. DOI: 10.1016/S0378-5955(03)00260-0

19 Van Ruijven MW, de Groot JC, Klis SF and Smoorenburg GF: The cochlear targets of cisplatin: An electrophysiological and morphological time-sequence study. Hear Res 205: 241-248, 2005. PMID: 15953532. DOI: 10.1016/j.heares.2005.03.023

20 Ravi R, Somani SM and Rybak LP: Mechanism of cisplatin ototoxicity: antioxidant system. Pharmacol Toxicol 76: 386-394, 1995. PMID: 7479581. DOI: 10.1111/j.1600-0773.1995. tb00167.x

21 Rybak LP, Whitworth CA, Mukherjea D and Ramkumar V: Mechanisms of cisplatin-induced ototoxicity and prevention. Hear Res 226: 157-167, 2007. PMID: 17113254. DOI: 10.1016/ j.heares.2006.09.015

22 Reiter RJ, Tan DX, Manchester LC, Pilar Terron M, Flores LJ and Koppisepi S: Medical implications of melatonin: receptor- 
mediated and receptor-independent actions. Adv Med Sci 52: 1128, 2007. PMID: 18217386.

23 Galano A, Tan DX and Reiter RJ: Melatonin as a natural ally against oxidative stress: a physicochemical examination. J Pineal Res 51: 1-16, 2011. PMID: 21752095. DOI: 10.1111/j.1600079X.2011.00916.X

24 Reiter RJ: Melatonin: The chemical expression of darkness. Mol Cell Endocrinol 79: C153-C158, 1991. PMID: 1936532. DOI: 10.1016/0303-7207(91)90087-9

25 Reiter RJ, Tan DX and Fuentes-Broto L: Melatonin: a multitasking molecule. Prog Brain Res 181: 127-151, 2010. PMID: 20478436. DOI: 10.1016/S0079-6123(08)81008-4

26 Lissoni P, Barni S, Mandalà M, Ardizzoia A, Paolorossi F, Vaghi M, Longarini R, Malugani F and Tancini G: Decreased toxicity and increased efficacy of cancer chemotherapy using the pineal hormone melatonin in metastatic solid tumour patients with poor clinical status. Eur J Cancer 35: 1688-1692, 1999. PMID: 10674014. DOI: $10.1016 /$ S0959-8049(99)00159-8

27 Gonzalez A, del Castillo-Vaquero A, Miro-Moran A, Tapia JA and Salido GM: Melatonin reduces pancreatic tumor cell viability by altering mitochondrial physiology. J Pineal Res 50: 250-260, 2011. PMID: 21118301. DOI: 10.1111/j.1600079X.2010.00834.X

28 Hill SM, Frasch T, Xiang S, Yuan L, Duplessis T and Mao L: Molecular mechanisms of melatonin anticancer effects. Integr Cancer Ther 8: 337-346, 2009. PMID: 20050373. DOI: 10.1177/ 1534735409353332

29 Ilbey YO, Ozbek E, Simsek A, Otunctemur A, Cekmen M and Somay A: Potential chemoprotective effect of melatonin in cyclophosphamide and cisplatin-induced testicular damage in rats. Fertil Steril 92: 1124-1132, 2009. PMID: 18829000. DOI: 10.1016/j.fertnstert.2008.07.1758

30 Surendran D, Geetha CS and Mohanan PV: Amelioration of melatonin on oxidative stress and genotoxic effects induced by cisplatin in vitro. Toxicol Mech Methods 22: 631-637, 2012. PMID: 22889322. DOI: 10.3109/15376516.2012.714009

31 Sener G, Satiroglu H, Kabasakal L, Arbak S, Oner S, Ercan F and Keyer-Uysa M: The protective effect of melatonin on cisplatin nephrotoxicity. Fundam Clin Pharmacol 14: 553-560, 2000. PMID: 11206705. DOI: 10.1111/j.1472-8206.2000. tb00440.x

32 Ateşşahin A, Şanna E, Türk G, Çeribaşi AO, Yilmaz S, Yüce A and Bulmuş O: Chemoprotective effect of melatonin against cisplatininduced testicular toxicity in rats. J Pineal Res 41: 21-27, 2006. PMID: 16842537. DOI: 10.1111/j.1600-079X.2006. 00327.x

33 Kaya H, Delibas N, Serteser M, Ulukaya E and Ozkaya O: The Effect of Melatonin on Lipid Peroxidation during Radiotherapy in Female Rats. Strahlentherapie Und Onkol 175: 285-288, 1999. PMID: 10392170. DOI: 10.1007/BF02743581

34 Vijayalaxmi, Meltz ML, Reiter RJ, Herman TS and Kumar SK: Melatonin and protection from whole-body irradiation: survival studies in mice. Fundam Mol Mech Mutagen 425: 21-27, 1999. PMID: 10082903. DOI: 10.1016/S0027-5107(98)00246-2

35 Jahnke G, Marr M, Myers C, Wilson R, Travlos G and Price C: Maternal and developmental toxicity evaluation of melatonin administered orally to pregnant Sprague-Dawley rats. Toxicol Sci 50: 271-279, 1999. PMID: 10478864. DOI: 10.1093/toxsci/ 50.2.271

36 Sookprasert A, Johns NP, Phunmanee A, Pongthai P, Cheawchanwattana A, Johns J, Konsil J, Plaimee P, Porasuphatana
S and Jitpimolmard S: Melatonin in patients with cancer receiving chemotherapy: A randomized, double-blind, placebo-controlled trial. Anticancer Res 34: 7327-7338, 2014. PMID: 25503168.

37 Lee JH, Yoon YM, Han YS, Yun CW and Lee SH: Melatonin promotes apoptosis of oxaliplatin-resistant colorectal cancer cells through inhibition of cellular prion protein. Anticancer Res 38: 19932000, 2018. PMID: 29599315. DOI: 10.21873/anticanres. 12437

38 Mills E, Wu P, Seely D and Guyatt G: Melatonin in the treatment of cancer: A systematic review of randomized controlled trials and meta-analysis. J Pineal Res 39: 360-366, 2005. PMID: 16207291. DOI: 10.1111/j.1600-079X.2005.00 258.x.

39 Wang YM, Jin BZ, Ai F, Duan CH, Lu YZ, Dong TF and Fu QL: The efficacy and safety of melatonin in concurrent chemotherapy or radiotherapy for solid tumors: a meta-analysis of randomized controlled trials. Cancer Chemother Pharmacol 69: 1213-1220, 2012. PMID: 22271210. DOI: 10.1007/s00280-012-1828-8

40 Hara M, Yoshida M, Nishijima H, Yokosuka M, Iigo M, OhtaniKaneko R and Shimada A: Melatonin, a pineal secretory product with antioxidant properties, protects against cisplatin-induced nephrotoxicity in rats. J Pineal Res 30: 129-138, 2001. PMID: 11316323. DOI: 10.1034/j.1600-079X.2001.300301.x

41 Parlakpinar H, Sahna E, Ozer MK, Ozugurlu F, Vardi N and Acet A: Physiological and pharmacological concentrations of melatonin protect against cisplatin-induced acute renal injury. $\mathrm{J}$ Pineal Res 33: 161-166, 2002. PMID: 12220331. DOI: 10.1034/j.1600-079X.2002.02910.X

42 Mercantepe F, Mercantepe T, Topcu A, Yilmaz A and Tumkaya L: Protective effects of amifostine, curcumin, and melatonin against cisplatin-induced acute kidney injury. Naunyn Schmiedebergs Arch Pharmacol 391: 915-931, 2018. PMID: 29860655. DOI: 10.1007/s00210-018-1514-4

43 Kilic U, Kilic E, Tuzcu Z, Tuzcu M, Ozercan IH, Yilmaz O, Sahin F and Sahin K: Melatonin suppresses cisplatin-induced nephrotoxicity via activation of Nrf-2/HO-1 pathway. Nutr Metab (Lond) 10: 1-8, 2013. PMID: 23311701. DOI: 10.1186/ 1743-7075-10-7

44 Tsuyoshi H, Orisaka M, Fukuda S, Hattori K, Tsang BK and Yoshida Y: Protective effect of dienogest on chemotherapyinduced reduced fertility in female rats. Steroids 93: 1-7, 2015. PMID: 25449767. DOI: 10.1016/j.steroids.2014.10.010

45 Haghi-Aminjan H, Asghari MH, Farhood B, Rahimifard M, Hashemi Goradel $\mathrm{N}$ and Abdollahi M: The role of melatonin on chemotherapy-induced reproductive toxicity. J Pharm Pharmacol 70: 291-306, 2018. PMID: 29168173. DOI: 10.1111/jphp.12855

46 Ye LF, TAO ZZ, HUA QQ, Xiao BK, Zhou XH, Li J and Yuan YL: Protective effect of melatonin against gentamicin ototoxicity. J Laryngol Otol 123: 598-602, 2009. PMID: 18957160. DOI: $10.1017 /$ S002221510800385X

47 Lopez-Gonzalez M a, Guerrero JM, Torronteras R, Osuna C and Delgado F: Ototoxicity caused by aminoglycosides is ameliorated by melatonin without interfering with the antibiotic capacity of the drugs. J Pineal Res 28: 26-33, 2000. PMID: 10626598. DOI: 10.1034/j.1600-079X.2000.280104.x

Received February 24, 2019 Revised April 7, 2019 Accepted April 8, 2019 